\title{
Diffuse pulmonary fibrosis and bilateral pneumothoraces in systemic lupus erythematosus
}

\author{
ANTHONY J. RICHARDS \\ M.B., M.R.C.P., D.Phys.Med. \\ I. C. TALBOT \\ M.B., B.S., M.R.C.Path. \\ $*$ D. R. SWINSON \\ M.B., M.R.C.P., D.Phys.Med. \\ E. B. D. HAMILTON \\ M.B., F.R.C.P., D.Phys.Med. \\ Departments of Rheumatology and Morbid Anatomy, King's College Hospital and Medical School, \\ Denmark Hill, London
}

\section{Summary}

A case of systemic lupus erythematosus (SLE) which developed extensive pulmonary fibrosis and bilateral pneumothoraces is reported. Other features of SLE were minimal. Diffuse fibrosing alveolitis in SLE is probably more common than has previously been thought.

Pleuropulmonary involvement in systemic lupus erythematosus (SLE) is not rare although it rarely dominates the other clinical features of the disease. The pulmonary manifestations are often only discovered post mortem and include pleuritis with effusions, atelectasis and bronchopneumonia (Purnell, Baggenstoss and Olsen, 1955).

In a review of respiratory system changes in 24 patients with SLE, Hoff brand and Beck (1965) were unable to find a single case in the literature of diffuse interstitial pulmonary fibrosis complicating SLE, but more recently Holden (1973) has reported a case of SLE with very extensive pulmonary fibrosis, and Olsen and Lever (1972) found intra-alveolar fibrosis in three patients with SLE, two of whom also had scleroderma.

The case presented here is unusual in that the respiratory symptoms were the dominant feature of the patient's illness, and in addition to crippling interstitial pulmonary fibrosis she developed bilateral pneumothoraces.

\section{Case report}

This 34-year-old West Indian lady was first seen in the out-patient department, King's College Hospital, in April 1972. She gave a two-month history of pain and swelling of the hands, ankles and feet. She also compained of pain without swelling in the wrists, shoulders and elbows. She had

* Present adress: Department of Rheumatology, Wrightington Hospital, Wigan, Lancashire WN6 9EP. developed a productive cough with purulent sputum and was dyspnoeic on exertion. In addition she had suffered from intermittent central chest pain of a dull aching character since March 1972. She was admitted for investigation and treatment in May 1972. Her past medical history was unremarkable.

\section{On examination}

Temperature $37 \cdot 5^{\circ} \mathrm{C}$. She was not clinically anaemic or cyanosed. There was no skin rash and no clubbing. She was dyspnoeic at rest and the respiratory rate was $30 / \mathrm{min}$ with equal chest movement. The pulse was $86 / \mathrm{min}$, regular and of good volume. There were no heart murmurs or signs of cardiac failure. B.P. 120/80 $\mathrm{mmHg}$. There were crepitations at both lung bases on auscultation but the breath sounds were vesicular. There was no hepatosplenomegaly or lymphadenopathy and no abnormality of the central nervous system.

\section{Investigations}

HB. $14.6 \mathrm{~g} / 100 \mathrm{ml}$, white cell count $6,900 / \mathrm{mm}^{3}$, differential white cell count and platelet count normal. E.S.R. (Westergren) $30 \mathrm{~mm} / 1 \mathrm{hr}$. Blood urea $20 \mathrm{mg} / 100 \mathrm{ml}$, electrolytes normal. Serum proteins showed slightly raised gamma globulin. Urine-no proteinuria. LE cells positive. DNA binding $42 \%$ (normal range $0-30 \%$ ). Rose Waaler and latex tests negative.

Lung function tests on admission: $\mathrm{FEV}_{1} 0.9$ litres (predicted 2.7 litres, VC1.1 litres (predicted 2.9 litres), $\frac{\text { FEV }_{1}}{\text { VC }} 81 \%$, CO diffusing capacity (D CO) $6.2 \mathrm{ml} / \mathrm{min} /$ $\mathrm{mmHg}$ (predicted 26.5). Radiographs of the chest on admission showed illdefined areas of consolidation in all zones of the lungs, maximal at the bases (Fig. 1). Radiographs of the hands, feet, knees, pelvis and sacro-iliac joints showed no abnormality. An electrocardiogram showed sinus rhythm with widespread 


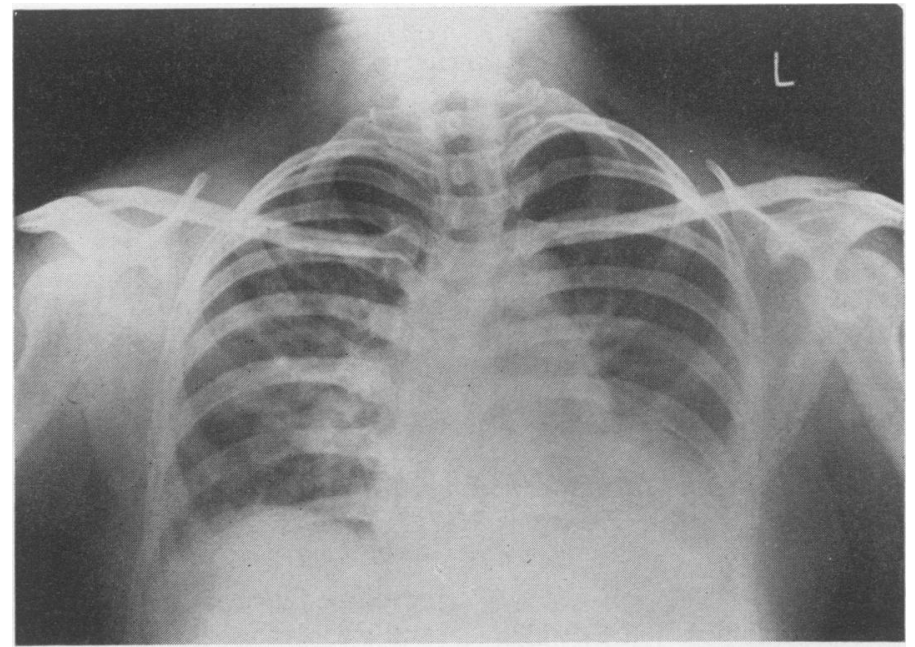

Fig. 1. Diffuse pulmonary fibrosis, maximal at the lung bases.

T wave inversion. An ultrasonic scan of the heart showed no evidence of a pericardial effusion.

\section{Progress}

In view of the recent chest infection and radiological appearance, the patient was treated on admission with ampicillin $500 \mathrm{mg}$ four times a day and enteric-coated aspirin for pain. One week after admission she was started on prednisone $10 \mathrm{mg}$ three times a day. A repeat chest X-ray showed no significant change from the previous one. The joint pains gradually subsided and she was no longer coughing up purulent sputum, but four weeks after $\mathbb{D}$ admission the patient suddenly developed surgical $\Phi$ emphysema of the soft tissues of the neck. A ches $\mathrm{X}$-ray showed small bilateral pneumothoraces and mediastinal emphysema (Fig. 2). The ill definea $\vec{\varphi}$ areas of shadowing in both lungs were unchanged. oे Arterial blood pH was 7.44 (normal 7.38-7.42 $\mathrm{pO}_{2} 60 \mathrm{mmHg}$ (normal 75-95 $\mathrm{mmHg}$ ), $\mathrm{pCO}_{2}$ $37 \mathrm{mmHg}$ (normal $38-42 \mathrm{mmHg}$ ).

The patient underwent lung biopsy under general anaesthesia, the terminal part of the lingula being $\stackrel{\square}{\AA}$ removed through a left thoracotomy incision.

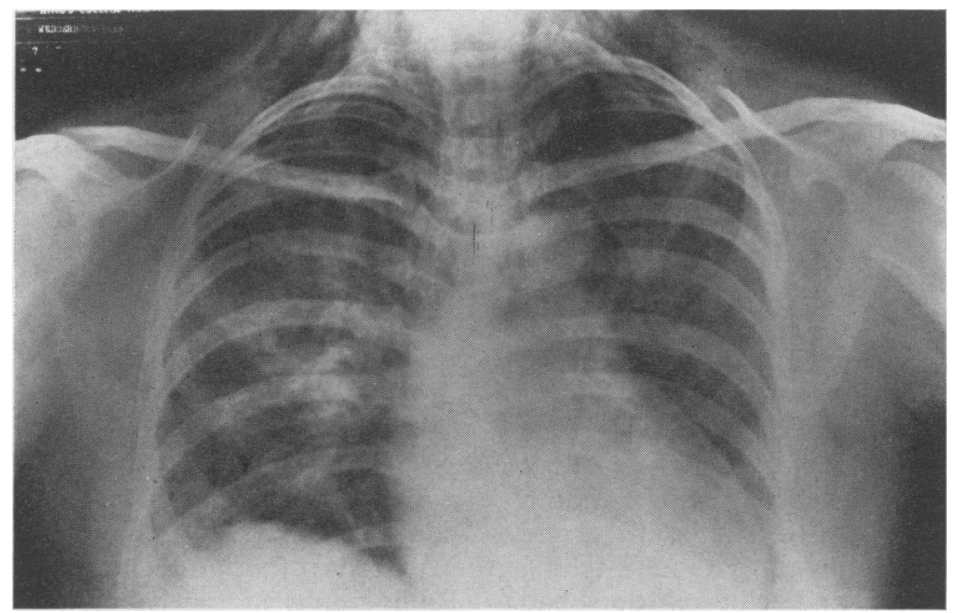

FIG. 2. Chest $\mathrm{X}$-ray showing extensive surgical emphysema. There are also mediastinal emphysema and bilateral pneumothoraces. 
Pleural drains were inserted into the right and left apical spaces and connected to underwater seal drainage. Bronchoscopy was also carried out and this revealed no abnormality. Histological examination of the lingula showed focal areas of interstitial fibrosis and inflammation. The blood vessels appeared normal and there was no evidence of granulomatous inflammation. Postoperatively she was pyrexial with purulent sputum which grew Klebsiella sp. on culture. She was given ampicillin and cloxacillin orally, $1 \mathrm{~g}$ of each drug four times a day and oxygen via nasal cannulae. Prednisone was continued at an increased dose of $20 \mathrm{mg}$ three times a day, the patient having been given intramuscular hydrocortisone during the operation and immediate postoperative period. Repeated examinations of sputum revealed no malignant cells or acid-fast bacilli. Repeat chest radiographs showed a persisting right pneumothorax (Fig. 3) which cleared within a few days, only to be followed by a left pneumothorax. Two days later, however, there was no radiological evidence of a pneumothorax although there was pulmonary oedema in both mid zones and the left lower zone. Ampicillin and cloxacillin were continued and the prednisone was reduced to $10 \mathrm{mg}$ four times a day. The following day the patient had a cardiac arrest and could not be resuscitated. The time interval between the onset of pneumothoraces and death was 2 weeks.

At autopsy there was a tension pneumothorax on the right and a smaller pneumothorax on the left. There were no pleural effusions or adhesions. The pulmonary arteries and bronchi were normal. Both lungs were collapsed and fairly firm but could be inflated via the main bronchi to normal size with $10 \%$ formol saline. The cut surface of both lungs after fixation in inflation was pale and firm, the alveolar septa thickened and the air spaces reduced (Fig. 4), but there were a few small areas which appeared macroscopically normal. No bullae were present. Histological examination of the abnormally firm lung tissue showed the features of diffuse fibrosing alveolitis, namely marked fibrous thickening of the alveolar walls with some lymphocytic infiltration (Fig. 5). There was no histological abnormality in the areas of lung which appeared macroscopically normal. The pericardium contained $30 \mathrm{ml}$ of blood-stained fluid, and the heart weighed $382 \mathrm{~g}$ with right ventricular hypotrophy. The heart valves and coronary arteries were normal. The oesophagus and the rest of the gastrointestinal tract were normal. Histological examination of the kidneys and interphalangeal joints of the fingers revealed no abnormality. The brain and cerebral vessels showed no abnormality. The bone marrow was normal; the spleen congested.

\section{Discussion}

This patient fulfilled the criteria for the diagnosis of SLE in that she presented with arthritis without deformity, had positive LE cells, and a raised DNAbinding activity of $42 \%$ in her serum. This degree of DNA-binding indicates that anti-DNA antibodies against native DNA are present and these antibodies are specific for SLE (Hughes, 1971).

The use of penicillins could be questioned in that they are sensitizers to drug-induced SLE. However, considering the already established disease before their use and the relatively short duration of the illness after, it is unlikely that they contributed to the immunopathology or had any adverse effect on the patient.

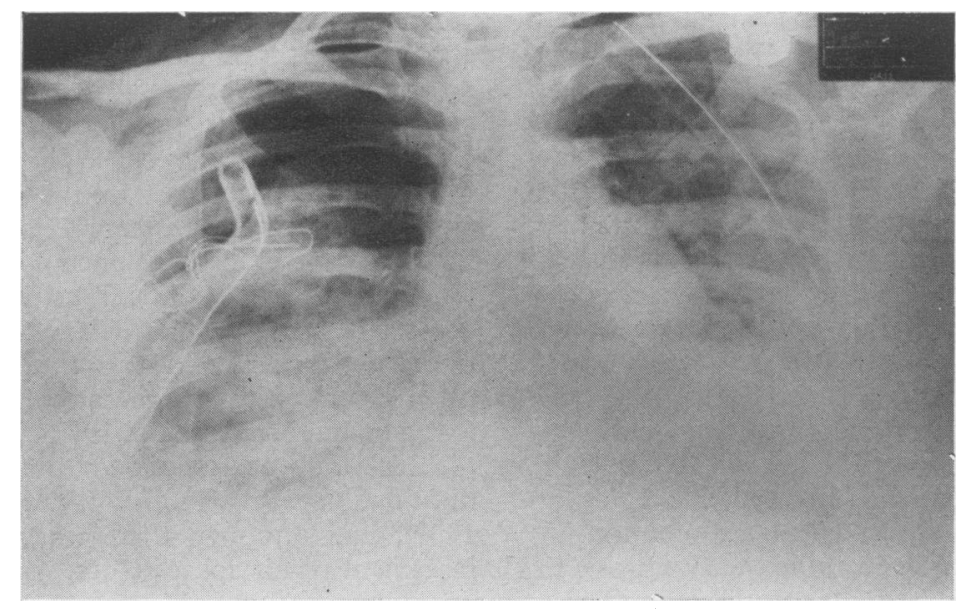

Fig. 3. Right sided pneumothorax. Pleural drains in situ. 


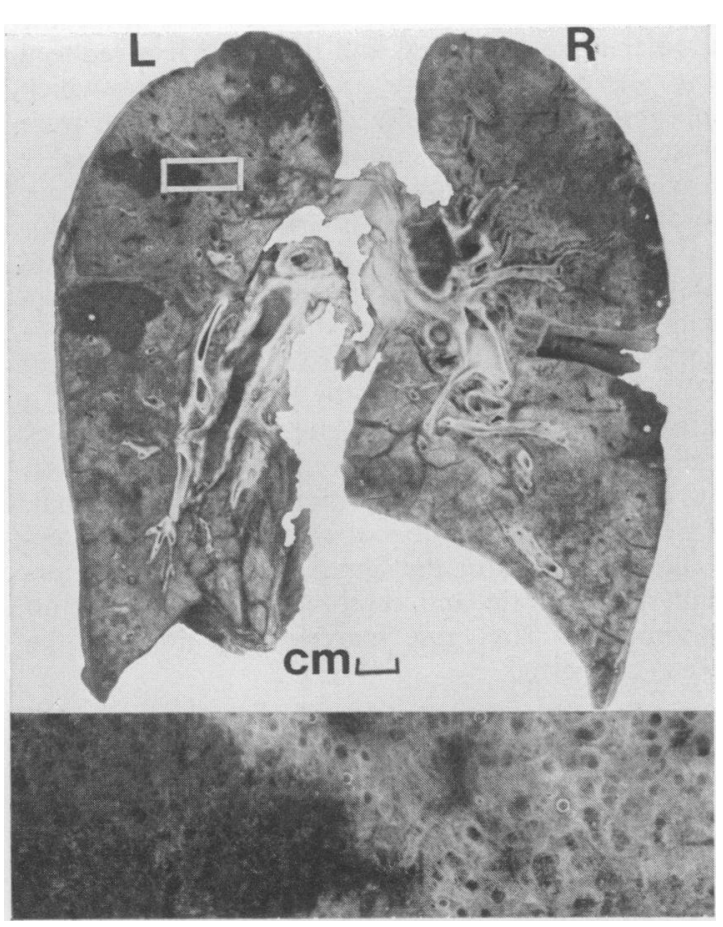

Fig. 4. (Top) Slice of each lung after inflation and fixation with area outlined shown in close-up (bottom). The pale areas are abnormally firm with a coarser pattern than the fine alveolar structure in the darker, normal areas. The normal areas occupy the upper portions of the lobes only.

Abnormalities of pulmonary function are well recognized in SLE (Dubois, 1966; Huang and Lyons, 1966), even though there may be no respiratory symptoms or radiological abnormalities. The diffusing capacity or transfer factor has recently been shown to be below the normal range in half of a small group of patients with SLE, with poor correlation between radiological findings and transfer factor values (Laitinen, Salorinne and Poppius, 1973). This patient's lung function tests showed a severe restrictive ventilatory defect with a very low diffusing capacity. Small, stiff lungs have been reported in SLE giving rise to severe dyspnoea, the main pathological change proposed being alveolar atelectasis (Hoffbrand and Beck, 1965). The diffusing capacities of Hoffbrand and Beck's patients were within normal limits though in the lower range. By contrast the diffusing capacity in the present case was markedly reduced at $6.2 \mathrm{ml} / \mathrm{min} / \mathrm{mmHg}$ against a predicted value of 26.5 , and there was marked thickening of the alveolar walls on histological examination. A recent case report of massive pulmonary fibrosis in SLE by Holden (1973) is similar to the present case in that other features of SLE were minimal. Holden's

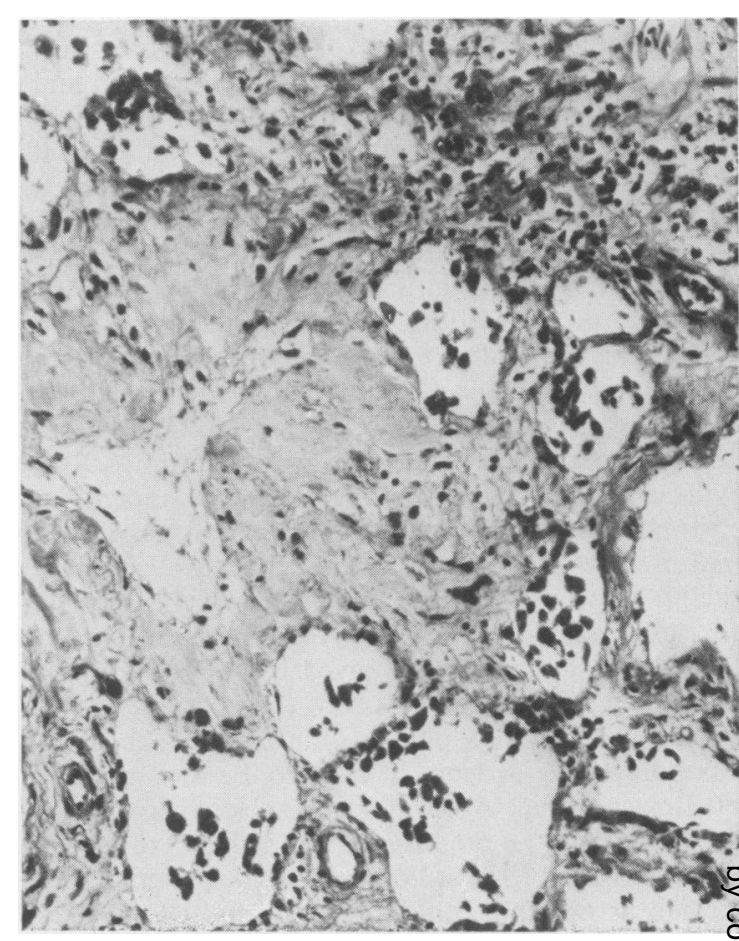

FIG. 5. Section of the abnormal, firm lung tissue, showing irregular widening of septa by poorly cellular fibrous tissue (mural fibrosis). A small number of mixed inflammatory cells are present. (H and $\mathrm{E}$ stained section, magnification $\times 180$.)

patient also had a restrictive ventilatory defect, and there was extensive fibrosis and cystic dilatation of both lungs on histological examination. Measurements of diffusing capacity were not reported.

An unusual feature of this patient's illness was the sudden onset of mediastinal emphysema and bilateral pneumothoraces. There is a previous case report of recurrent pneumothoraces complicating SLE (Sawkar and Easom, 1971) where radiographs revealed cystic changes in the pulmonary parenchyma, and small sub-pleural cysts were found at thoracotomy. When a pneumothorax occurs in diffuse fibrosing alveolitis, it usually follows rupture of a bleb or cyst (Dines, Clagett and Good, 1967), or it may occur as a result of extensive pleural involvement with accompanying pleural effusion (Mundy and MacDonald, 1972). In the present case the histology corresponded to the mural type of diffuse fibrosing alveolitis (Scadding and Hinson, 1967), and although there was minor diffuse enlargement of air spaces (Figs. 4 and 5), there were no bullae, and no obvious cause for the pneumothoraces was found at autopsy. 
The pathogenesis of the pulmonary fibrosis is also unknown. It is tempting to suggest that it commences from the deposition of autoimmune complexes, but this patient had no evidence of the glomerular damage that is usually found if circulating immune complexes are present. Unfortunately, no immunological studies were carried out on the patient's lungs.

\section{Acknowledgments}

We are grateful to Dr Roger Williams for permission to publish details of this patient who was under his care, and Mr George Harwood for technical assistance.

\section{References}

Dines, D.E., ClagetT, O.T. \& Good, C.A. (1967) Nontuberculous pulmonary parenchymal conditions predisposing to spontaneous pneumothorax. Journal of Thoracic and Cardiovascular Surgery, 53, 726.

DuвoIs, E.L. (1966) Lupus Erythematosus, p. 172. McGrawHill Book Company Inc., New York Blakiston Division.

HoFFBRAND, B.I. \& BECK, E.R. (1965) 'Unexplained' dyspnoea and shrinking lungs in systemic lupus erythematosus. British Medical Journal, 1, 1273.
Holden, M. (1973) Massive pulmonary fibrosis due to $\vec{\Phi}$ systemic lupus erythematosus. New York State Journal of $\varrho$ Medicine, 73, 462.

HuANG, C.T. \& Lyons, H.A. (1966) Comparison of pulmonary function in patients with systemic lupus erythema- $\stackrel{\rho}{\rightarrow}$ tosus, scleroderma, and rheumatoid arthritis. American $\bar{C}$ Review of Respiratory Diseases, 93, 865.

Hughes, G.R.V. (1971) Significance of Anti-DNA antibodies in systemic lupus erythematosus. Lancet, ii, 861.

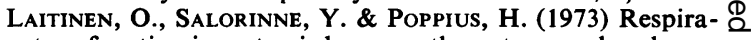
tory function in systemic lupus erythematosus, scleroderma nు and rheumatoid arthritis. Annals of the Rheumatic Diseases, 32, 531.

MuNDY, G.R. \& MacDonald, C.B. (1972) Atypical presentations of diffuse fibrosing alveolitis. British Journal of Diseases of the Chest. 66, 261.

Olsen, E.G.J. \& Lever, J.V. (1972) Pulmonary changes in systemic lupus erythematosus. British Journal of Diseases of the Chest, 66, 71 .

Purnell, D.C., Baggenstoss, A.H. \& Olsen, A.M. (1955) i Pulmonary lesions in systemic lupus erythematosus. Annals of Internal Medicine, 42, 619.

SAWKAR, L.A. \& EASOM, H.F. (1971) Recurrent spontaneous pneumothoraces in systemic lupus erythematosus. Chest, of 60, 604.

Scadding, J.G. \& Hinson, K.F.W. (1967) Diffuse fibrosing 윽 alveolitis (diffuse interstitial fibrosis of the lungs). Correlation of histology at biopsy with prognosis. Thorax, 22, 291.

\section{Addendum}

The authors of a recent paper* reviewing diffuse interstitial lung disease in SLE could find no cause for the lung lesions in this condition. The participation of SLE in the disease processes in the lungs is unresolved.
* Eisenberg, H., Dubois, E.L., Sherwin, R.P. \& Balchu O.J. (1973) Diffuse interstitial lung disease in systemic lupus erythematosus. Annals of Internal Medicine, 79, 37.

\section{Pancreatitis and the pill}

\author{
I. P. F. Mungall \\ M.B., B.Chir., M.R.C.P.
}

\author{
R. V. Hague \\ M.B., Ch.B., M.R.C.P.
}

The Royal Hospital, West Street, Sheffield S1 3SR

\section{Summary}

An association between acute relapsing pancreatitis and the contraceptive pill has recently been suggested (Bank and Marks, 1970; Davidoff, Tishler and Rosoff, 1973). We wish to report a further case of acute pancreatitis in a patient taking the pill. In contrast to previous cases the serum lipids were normal and the pancreatitis was severe and ultimately fatal.

\section{Case report}

A thirty-four-year-old housewife and mother of eight had been on a combined contraceptive pill (ethinyloestradiol and megestrol acetate) since 1969.
In June 1973 she developed severe, recurrent attacks of upper abdominal pain and vomiting. She had previously been healthy and there was no history of alcoholism. Her general practitioner suspected gallstones and referred her for a surgical opinion in November, 1973. She was noted to be obese but there were no specific physical signs and she failed to attend for investigation.

In December 1973 she was admitted to the Casualty Department having suddenly collapsed with central and left-sided chest pain. She discharged herself before she could be assessed, only to be readmitted a few hours later with a recurrence of 